\title{
Micro-fracture Toughness in A Nanoceramic Composite
}

\author{
Zhong Ling, Yongli Wu \\ LNM, Institute of Mechanics, Chinese Academy of Sciences, Beijing 100080, P.R.China \\ Email:lingz@lnm.imech.ac.cn
}

\begin{abstract}
Micro-fracture toughness in one nanoceramic composite, $\mathrm{Al}_{2} \mathrm{O}_{3} / \mathrm{SiC}_{\text {nano, }}$ is measured by Nanoindentation tests. Microscopy is adopted to probe that all nanoindentations are local at $\mathrm{Al}_{2} \mathrm{O}_{3}$, matrix component of the current composite and measure length of radial micro-cracks at corners of nanoindentation. The measured fracture toughness at the shallow indentatiois is higher than those at deeper ones. Relations between micro-toughness and peak loads as well as peak depths are discussed. And an analysis to the energy consumed during the indentation and fracture toughness explained that, the lower fracture toughness measured in the deeper impression probably resulted from its fracture modes yielded by higher load and larger depth.
\end{abstract}

Keywords: Micro-fracrure toughness, nanoceramic composite, nanoindentation

\section{Introduction}

Nano-ceramic matrix composites are ceramics containing nanosize-ceramic particles of $0.1-0.5 \%$ volume fractions. The nanosizeparticle dispersed within grains of matrix would lead to a change in the fracture mode, from predominantly inter-granular to predominantly trans-granular fracture, and enhance fracture toughness of the composite. A great attention has been paid to these toughening mechanisms in last decades and the researches focused on theoretical micro-stress analysis on the particle and matrix around the particle, microscopic observation to the composite's microstructure and, macroscopic mechanical experiments on strength, fracture and fracture toughness of the composite $[1,2]$. However, due to lack of quantitative description for their properties at much smaller scale, some links between micro-model analysis and macro-mechanical properties still need to be better understood for the ceramic composite, such as (i) micro-fracture strength of grain of matrix containing nanoparticles; (ii) distribution of residual stress or strain field in matrix due to thermal mismatch in composite or monolithic; (iii) fracture toughness at very tiny volume.
Nanoindentation is a technique developed over last years and its principle advantage is to probe the mechanical properties of materials at the very small scale $(\mathrm{nm} \sim \mu \mathrm{m})$ during loading and unloading. Many researches are presented on the technique's mechanisms and applications to measure mechanical properties at tiny volume of material, such as Young's modulus, hardness, yield stress, strain hardening and micro-strength as well as fracture toughness $[3,4]$. Motivated by these researches, we employed Nanoindenter to a typical nanocomposite, $\mathrm{Al}_{2} \mathrm{O}_{3} / \mathrm{SiC}_{\text {nano, }}$, and experimentally study fracture toughness of the composite at very tiny volume. Microscopic observations are performed with care to make sure each indentation location and measure length of radial microcracks at corners of the indentations.

\section{Experimental Procedure}

\subsection{Material \& Testing Conditions}

Current material is $\mathrm{Al}_{2} \mathrm{O}_{3} / \mathrm{SiC}_{\text {nano }}$ made via high temperature sintered. The matrix in the composite is consisted of $\mathrm{Al}_{2} \mathrm{O}_{3}$ and some $\mathrm{ZrO}_{2}$, $\mathrm{Al}_{2} \mathrm{O}_{3}: \mathrm{ZrO}_{2}=92: 8$. Volume fractor of $\mathrm{SiC}$ particles in whole composite is about $10 \mathrm{vol} . \%$. 
The Table 1 shows the principle parameters of the composite. Figure 1 is the micrograph of original material and three components, $\mathrm{Al}_{2} \mathrm{O}_{3}$ and $\mathrm{ZrO}_{2}$ and $\mathrm{SiC}$, could be seen. Because $\mathrm{ZrO}_{2}$ always are used to coast $\mathrm{SiC}$ particles before process, cluster of $\mathrm{SiC}$ particles with $\mathrm{ZrO}_{2}$ could be seen in this composite and with dark color in micrographs (see Figure 1).

Nanoindentation tests are performed under nanoindenter, Nano Indenter $\boldsymbol{X P}$, with Cube-corner indenter, which is very effective in brittle material fracture toughness measurement; the maximum load on the tip is set as 50 , $100 \mathrm{mN}$, and the loading rate $0.1 \mathrm{~nm} / \mathrm{s}$.

Optical microscopy, Polyvar-met, with image-system, is applied to make sure locations of each indentation and measurement of length

\begin{tabular}{lcc}
\hline Component & $\mathrm{Al}_{2} \mathrm{O}_{3}: \mathrm{ZrO}_{2}$ & $\mathrm{SiC}$ \\
\hline fractor & $92: 8$ & $10 \mathrm{vol} \%$ \\
\hline Grain Size & $5 \mu \mathrm{m}$ & $0.1 \mu \mathrm{m}$ \\
\hline
\end{tabular}

Tablel Main parameters in the composite

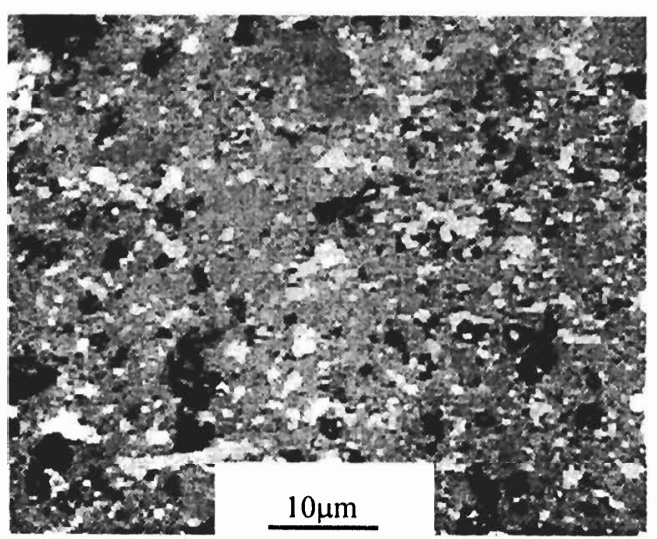

Figure 1.Micrograph of original material. of radial microcracks at corners of an indentation.

\subsection{Experimental Observations}

(I) Micro-fracture toughness measurement

Fracture toughness at small scale can be measured by ultra-low load indentation using techniques for nanoindentation testing [3]. It is developed with the techniques to measure radial cracking which occurs when brittle materials are indented by a sharp indenter. The simple relationship exists between the fracture toughness and the length of the radial cracks, i.e. $K_{c}=\alpha\left(\frac{E}{H}\right)^{\frac{1}{2}}\left(\frac{P}{c^{3 / 2}}\right)$. Where $K_{c}$ is fracture toughness and $c$ is length of radial crack at corners of indentation, $E, H$ is Young's modulus, micro-hardness of the material, respectively. Particularly $P$ is peak load on the indenter and $\alpha$ is an empirical parameter that depends on the geometry of the indenter, for cube-corner tip, $\alpha=0.04$. Obviously, $E, H$ can be determined directly from nanoindentation load-displacement data. More details on fracture toughness measurement by nanoindentation cracking methods are presented in reference [3].

\section{(II) Nanoindentation testing data}

Total three groups of nanoindentation test performed by Nanoindenter. Two different peak loads on indenter are chosen as $50 \mathrm{mN}$ and $100 \mathrm{mN}$ for current fracture toughness measurements. Typical curves of loading-depth in nanoindentation tests are showed in Figure 2, $50 \mathrm{mN}$ peak load (Figure 2a) and $100 \mathrm{mN}$ peak load (Figure 2b). There are some steps in load-depth curves. It seems that indenter-tip meets porous or microcracking occurs while indenting. So the tip goes deeper but load on tip does not increase, or load goes as constant due to less the resistance from the contact surface, e.g. sample \#610_100_2,5 and 610 2 3. As showed in Figure $\overline{2}$, such cases always appeared under higher loads, saying $100 \mathrm{mN}$.

Microcracking at corners of an impression is checked under high magnifications. In tests with $50 \mathrm{mN}$ of peak load, micro-radial cracking occurred at 5 of 10 impressions; in those with $100 \mathrm{mN}$ of peak load, micro-radial cracking exists 3 of 5 impressions. Particular in cases of radial microcracking, hardly few steps appeared in their load-depth curves (Figure 2).

Figure 3 showed that a typical graph of an impression for radial crack length measurement. Triangle-liked impression is local at matrix of current ceramics, $\mathrm{Al}_{2} \mathrm{O}_{3}$, and radial cracks would be seen along corners of the impression. By Image-analysis under higher magnifications, one 
would calculate out fracture toughness based on the radial crack length. Young's modulus and hardness of the composite have been measured by standard nanoindentation techniques for the same composite [5]. In current tests, since almost all indentations are local at the matrix of the composite, the Young's modulus and hardness are $420 \mathrm{GPa}$ and $26 \mathrm{GPa}$, respectively.

610_Kc_2 (50tr)

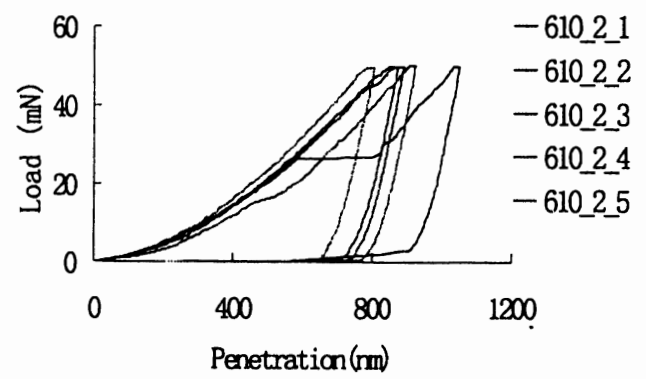

(a) peak load $=50 \mathrm{mN}$;

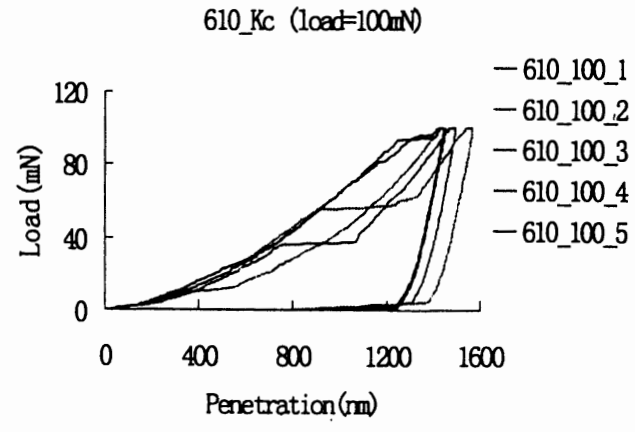

(b) peak load $=100 \mathrm{mN}$

Figure 2. Typical testing curves of load and

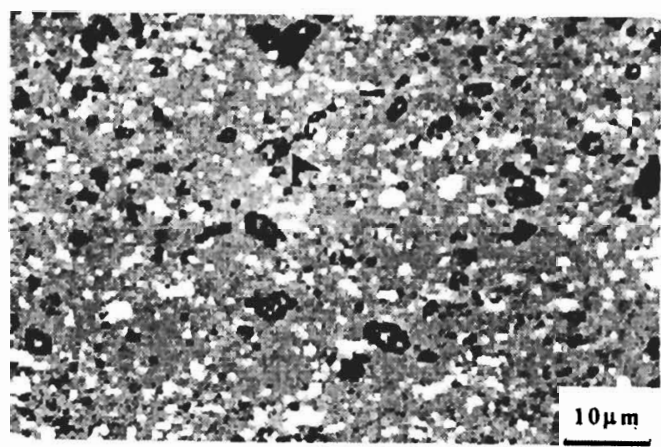

Figure3 Micrograph of an indentation (remarked, peak load $=50 \mathrm{mN}$ )

\section{Results and Discussions}

\subsection{Fracture toughness-peak load}

It is clear that micro- cracking does not occur at all indentations. Figure 4 showed microcrackings occurred and fracture toughness measured indentations tests under $50 \mathrm{mN}$ peak loads. The fracture toughness measured at current composite changed a little bit with slight-load change, 49.7-50.1 mN (see Figure 4). So did those under $100 \mathrm{mN}$ peak load. Its average fracture toughness is $5.1\left(\mathrm{MPa} \cdot \mathrm{m}^{05}\right)$ under $50 \mathrm{mN}$ peak load, $3.8\left(\mathrm{MPa} \cdot \mathrm{m}^{05}\right)$ under $100 \mathrm{mN}$ peak load. The toughness measured under $100 \mathrm{mN}$ peak load is less than that under $50 \mathrm{mN}$ peak load, $34 \%$. Figure 5 gives the difference between two toughness values under both peak loads.

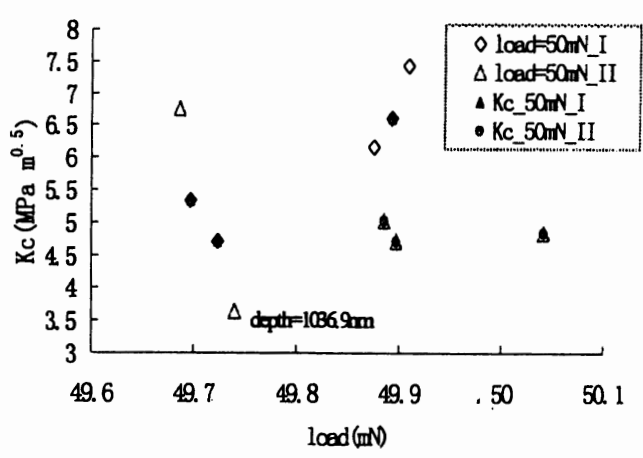

Figure 4. Micro-toughness vs. peak load (shadowy means microcracking)

\subsection{Fracture toughness-peak depth}

Obviously, the load on the indenter determined the depth of indenter. Thus the fracture toughness got under $50,100 \mathrm{mN}$ peak loads of course related to the tip's depth. Figure 6 presented the measured toughness under different peak depths. The toughness measured at small volume indeed changed with the maximum depth. The deeper the impression is, the less toughness is measured. Is it size effect for materials' toughness?

As stated above, radial cracks always appeared in shallower impressions (lower loads) in current tests. And few steps are seen in the curves of load-depth for the impressions (Figure 
2a). It presents that, the radial cracks observed on the surface are resulted from initial fracture and, therefore for the shallow impressions, the measured toughness is the energy release rate while the first radial cracking occurred at initial fracture.

For the deeper impression, however, the work done by the load at the indentation would be greater than that of the shallow one. It is very obvious, higher load and larger depth would simply produce the larger area enclosed by load-depth curves. Nevertheless, for a deep impression, due to its larger contact area, the surface energy consumed may also be greater than that for the shallow one. As showed in

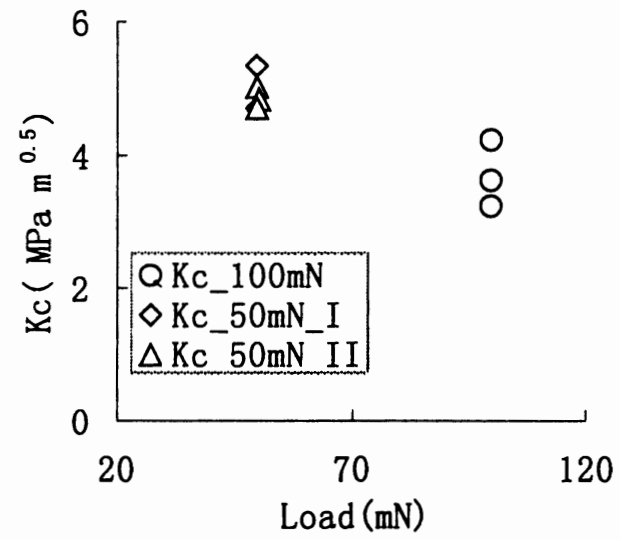

Figure 5. Micro-toughness varied with load

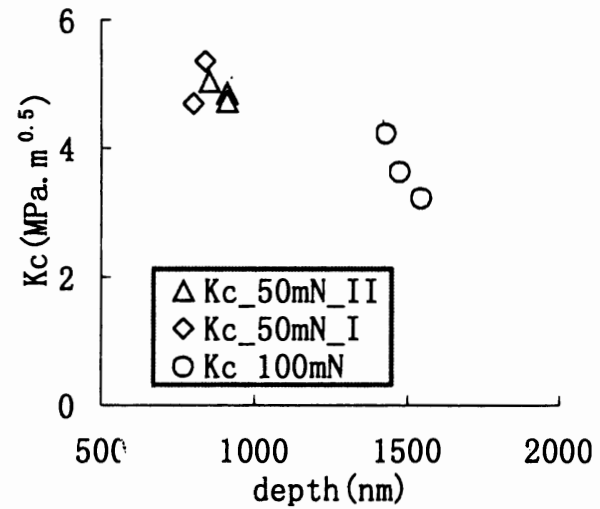

Figure 6. Micro-toughness varied with depth
Figure $2 \mathrm{~b}$, more steps occurred in load-depth curves before reached at the peak load. This represents that microcrack has been formed at some load level during indentation. Thus among the total energy, one part is consumed to form the microcrack, one to enlarge contact surface. And the remains are not enough to yield new microcrack on the surface. Thus no radial crack is seen at corners while steps appeared in load-depth curve.

Actually, even if in the cases of radial crack associated with steps in load-depth curve, it is hard to determine if the radial cracks occurred at the initial fracture. But the measured energy release rate was always based on the surface radial cracking and took no account of other fracture mode, therefore small fracture toughness with more scatters is appeared in deeper indentations showed in Figure 6.

\section{Acknowledgments}

This work is financially supported by NSFC (Grant No. 50172053) and key project from the Chinese Academy of Sciences (Grant No.KJCX2-SW-L2).

\section{References}

1. Evans,A.G. Design and life prediction issues for high-temperature engineering ceramics and their composites, Acta. Mater. 45(1) (1997) 23-40

2. Taya,M.et al, Toughening of a particulatereinforced ceramics-Matrix composite by thermal residual stress, J. Am. Ceram. Soc. 73(5)(1990) 1382-1391

3. Pharr,G.M. Measurement of mechanical properties by ultra-low load indentation, material Science \& Engineering, A253(1998) 151-159

4. Zeng, K. et al, An analysis of load-penetration curves from instrumented indentation, Acta Mater. 49(2001)3539-3551

5. Ling, Z. Nano-microscale characterizations to $\mathrm{Al}_{2} \mathrm{O}_{3} / \mathrm{SiC}_{\text {nano }}$ ceramic composites, Int. J. Nonl. Sci. \& Numerical Simulation, 3(3/4)(2002) 487-490 